\title{
Risk Assessment of Distribution Systems with Distributed Generation
}

\author{
Yuxiang Hou ${ }^{1}$, Minfang Peng ${ }^{1}$, Hongwei $\mathrm{Che}^{2}$, Jingying $\mathrm{Hou}^{2}$ and Liang $\mathrm{Zhu}^{2}$ \\ ${ }^{1}$ School of Electrical and Information Engineering, Hunan University, Changsha 410082, China \\ ${ }^{2}$ Hunan Electric Power Company, Changsha 410007, China
}

\begin{abstract}
Based on risk assessment theory and " $\mathrm{N}-1$ " safety criteria, aiming at the situation of fault and power recovery in distribution system with distributed generation (DG), load bus loss and line overload and they comprehensive risk index are proposed to assess the risk degree of system, and find the vulnerable nodes and lines through statistical analysis. At the same time based on the heuristic algorithm, the fault restoration scheme of power distribution system is proposed, which use the tie line to transfer load at first and then through DG islanding to restore power supply. Finally, taking IEEE 33 bus distribution system for example, calculation results in different conditions prove that these evaluation indexes can accurately reflect the risk degree of DG distribution network, and the scheme of failure recovery can effectively reduce the system risk, which can be regarded as reference for distribution network planning and risk prevention.
\end{abstract}

Keywords-distribution network; risk assessment; fault recovery; distributed generation; "N-1" security criterion; island classification; heuristic algorithm

\section{INTRODUCTION}

Take effective fault recovery measures to reduce system failure load loss and objectively evaluate correctly distribution is very important to ensure the safety of power distribution system[1]. Distribution network usually has the characteristics of closed loop design and open loop operation [2]. Traditional distribution network can restore fault area load by using tie line(TL) to transfer load[3]. Methods of traditional fault recovery mainly include heuristic algorithm[4] and artificial intelligence algorithm[5]. Now with the access of a large number of distributed generation(DG), distribution network from a single power supply radial network into many power supply network, and it can reduces the power loss and improve the system reliability through the islanding of blackout area[6].

This paper based on "N-1" safety criteria and build the system load bus loss risk and the line overload risk index and the comprehensive risk index, which considering the load power, low voltage and DG's probabilistic load loss of case, and through the statistics of the risk value to find system weak nodes and lines. At the same time based on the heuristic principle, this paper put forward the failure recovery strategy, which use the tie line to transfer load at first and then through DG islanding to restore power supply. Example results demonstrated the correctness and effectiveness of the proposed method, so it can guide the distribution network planning and risk prevention.

\section{THE MODEL OF COMPONENTS IN DISTRIBUTION NETWORK WITH DGS}

A. Wind power generation probability model

Weibull distribution is used to fitting the wind speed[7]:

$$
\begin{gathered}
f_{w}(v)=\left(\frac{2 \bullet v}{c^{2}}\right) \bullet \exp \left[-\left(\frac{v}{c}\right)^{2}\right] \\
P_{w}=\left\{\begin{array}{cc}
0 & , v \leq v_{c i} \quad \text { or } \quad v \geq v_{c o} \\
P_{r} \bullet\left(v-v_{c i}\right) /\left(v_{r}-v_{c i}\right) & , v_{c i}<v \leq v_{r} \\
P_{r} & , v_{r}<v \leq v_{c o}
\end{array}\right.
\end{gathered}
$$

Where $P_{w}$ is wind generator active output, $v$ is actual wind speed, $v_{c i}$ is cut-in wind speed, $v_{r}$ is rated wind speed, $v_{c o}$ is cutout wind speed, $P_{r}$ is maximum power output.

\section{B. Photovoltaic power generation probability model}

Beta distribution is often used to fitting the Solar illumination intensity approximately[7]:

$$
f_{P V}(r)=\frac{\Gamma(\alpha+\beta)}{\Gamma(\alpha) \bullet \Gamma(\beta)} \bullet\left(\frac{r}{r_{\max }}\right)^{\alpha-1} \bullet\left(1-\frac{r}{r_{\max }}\right)^{\beta-1}
$$

Where $r$ is the actual light intensity, $r_{\max }(W / m)$ is maximum intensity respectively; $\Gamma$ is the gamma function. $P_{P V}$ is active output, which is in direct proportion to the total area of the battery components $A$ and photoelectric conversion efficiency $\eta, P_{A V}=A \bullet \eta \bullet r$.

\section{Load Model}

The power supply of load is relatively stable,so in this paper regard it model as the constant load.

\section{COMPOSITION OF THE RISK ASSESSMENT INDICATORS}

\section{A. Risk Assessment Theory}

The operating risks of distribution network can be described as follow[8]:

$$
R\left(X_{t}\right)=P_{i}\left(E_{t}\right) \bullet S_{i}\left(X_{t} / E_{t}\right)
$$

In the above equations, $X_{t}$ is running state before the system fault; $E_{t}$ is uncertain accidents; $P_{i}\left(E_{t}\right)$ is appearance probability of $E_{t} ; S_{i}\left(X_{t} / E_{t}\right)$ is the consequences severity when $E_{t}$ happens; $S_{i}\left(X_{t} / E_{t}\right)$ is the risk parameter values. 


\section{B. The Probability Model of Line Fault}

During the evaluation time $T$ the line $j$ break down, the probability $\lambda_{E j}$ is calculated as follows:

$$
\lambda_{E j}=\lambda_{j} \prod_{j \notin \Lambda, k \in \Lambda}\left(1-\lambda_{k}\right)
$$

$\Lambda$ is the assembly of all the nodes and normal lines.

\section{The Construction of Evaluation Index}

When system Ej fault occurs, power distribution network with DG can be recovered through TL to transfer electric power and DG islanding, which can restore power supply to users. When DG supply power to users, the supply probability can be calculated by the formula:

$$
p_{D G}= \begin{cases}\int_{v_{G \min }}^{v_{r}} f_{w}(v) d v \quad, \quad D G \in \text { Wind Power } \\ p_{D a v} \bullet \int_{r_{G \min }}^{r_{\max }} f_{p v}(r) d r, & D G \in \text { Photovoltaic }\end{cases}
$$

In the above equations, $v_{G \min }, r_{G \min }$ respectively represent wind speed and illumination intensity when DG can meet the user needs. $p_{D a y}$ is the proportion of daytime of one day.

1) Load bus loss risk index: When $E_{j}$ fault occurs, all load bus of system are in three kinds of areas:connection area(I ), power supply interrupted area (II ) and power recover area by DG(III). The loss risk value $R_{i j}^{\text {Node }}$ of load bus $i$ under $E_{j}$ failure can be calculated by the formula:

$$
\begin{gathered}
L_{L V}=\left|1-V^{2}\right| \\
S_{L V}=\left\{\begin{array}{cc}
e^{L_{L V}}-1 & , e^{L_{L V}} \leq 2 \\
1 & , e^{L_{L V}}>2
\end{array}\right. \\
R_{i j}^{\text {Node }}=\left(p_{1}+p_{2} S_{L V}^{i j}\right)\left(\rho_{1} \frac{\lambda_{E_{j}} \mu_{i} n_{i}}{\sum_{k \in \varphi_{S C}} \mu_{k} n_{k}}+\rho_{2} \frac{\lambda_{E_{j}} \mu_{i} P_{i}}{\sum_{k \in \varphi_{S C}} \mu_{k} P_{k}}\right) \bullet \frac{t}{T}
\end{gathered}
$$

In the above equations, $\varphi_{S C}$ is the assembly of all the nodes and lines, $t$ is trouble duration, $\mu_{i}$ is the important degree of load bus $i, n_{i}$ is the number of users of load bus $i, \rho_{1}, \rho_{2}$ are proportionality coefficient. Because of the load point importance degree of load bus's users equal to the load bus's energy, so $\rho_{1}=\rho_{2}=0.5 . p_{1} 、 p_{2}$ respectively corresponding to the load bus' probability of power supply under three kinds of areas and have a discussion here:a)If the load bus is in I area, $p_{1}=0, p_{2}=0$;b)If the load bus is in II area, $p_{1}=1, p_{2}=0$; c)If the load bus is in III area, $p_{1}=1-p_{D G}^{k}, p_{2}=p_{D G}^{k}$. The loss risk value $R_{i}^{\text {Node }}$ of load bus $i$ under all failure can be calculated by the formula:

$$
R_{i}^{\text {Node }}=\sum_{E_{j} \in \varphi_{E t}} R_{i j}^{\text {Node }}
$$

In the above equations, $\varphi_{E t}$ is expected accident collection.

2) Line Overload Risk Index: When $E_{j}$ fault occurs, overload risk $R_{i j}^{\text {Line }}$ of line i can be calculated by the formula:

$$
\begin{gathered}
L_{O D}=\left\{\begin{array}{cc}
0 & L \leq a \\
L-a & L>a
\end{array}\right. \\
S_{O D}=e^{L_{O D}}-1
\end{gathered}
$$

$$
R_{i j}^{L \text { ine }}=p_{L \text { ine }} \bullet \frac{\lambda_{E j} S_{O D}^{i j}}{m_{0} S_{O D}^{0}} \bullet \frac{t}{T}
$$

In the above equations, $m_{0}$ is the number of all lines of system, when $L=1, S_{O D}=S_{O D}^{0}, a=0.8, p_{\text {Line }}$ is power supply probability of line under different areas and have a discussion here: a)If the load bus is in I area, $p_{\text {Line }}=1$; b)If the load bus is in II area, $p_{\text {Line }}=0$; c)If the load bus is in III area, $p_{\text {Line }}=p_{D G}^{k}$. The overload risk value $R_{i}^{\text {Node }}$ of line $i$ under all failure can be calculated by the formula:

$$
R_{i}^{\text {Line }}=\sum_{E j \in \varphi_{E t}} R_{i j}^{\text {Line }}
$$

3) System comprehensive risk index: When $E_{j}$ failure occurs, system comprehensive risk value not only contains the load bus loss risk but also contains the line overload risk value, so the comprehensive risk value $R_{E_{j}}$ and system comprehensive risk statistics value $R_{\text {Sys }}$ can be calculated by the formula:

$$
\left\{\begin{array}{c}
R_{E j}=\sigma_{1} \bullet R_{E j}^{N o d e}+\sigma_{2} \bullet R_{E j}^{\text {Line }} \\
R_{E j}^{N o d e}=\sum_{i \in \varphi_{\mathrm{sc}}} R_{i j}^{N o d e}, R_{E j}^{\text {Line }}=\sum_{i \in \varphi_{\mathrm{sc}}} R_{i j}^{L i n e} \\
R_{S y \mathrm{~s}}=\sum_{j \in \varphi_{E t}} R_{E j}
\end{array}\right.
$$

In the above equations, $\sigma_{1}=0.8, \sigma_{2}=0.2$.

\section{System FAult ReCOVERy SCHEME}

\section{A. The Output Power of Island Power Supply}

The transmission power of TL is less than $P_{T L}$, the maximum power supply power of DG is $P_{\max }$, and set the power supply range is $\mu(0<\mu<1)$, the output power of island power supply $P_{S}$ can be calculated by follow:

$$
P_{S}=\left\{\begin{array}{cl}
P_{T L} & , S \in T L \\
P_{\max } \bullet \mu & , S \in D G
\end{array}\right.
$$

\section{B. The Target of Islanding}

1) Priority to transfer power to fault outage area by $T L$.

2) More load bus with high load level should be included.

3) Load bus with more users should be restored.

\section{Constraint Condition}

1) Every island should be supplied with power by only one island power source $S$.

2) The output of island power source $S$ must be greater than the load demand.

\section{Algorithm and steps of islanding}

In this paper, based on heuristic search algorithm, steps are described as follows:

1)Mark the load bus $i$ of system is in the state of normal power supply $\left(M k_{i}=0\right)$ or fault power outage $\left(M k_{i}=1\right)$, and set all line of failure blackout area mark $L=1$, find the assembly of island power supply which can be put into use $S_{k} \in \Phi_{S}$, if 
$\Phi_{S} \neq \varnothing$, number $S_{k}\left(k=1,2, \ldots, N_{S}\right)$ in $\Phi_{S}$, begin the process of island search from $S_{k}(k=1)$, otherwise end the the process of system islanding.

2)Find load bus $i\left(M k_{i}=1\right)$ which link to $S_{k}$ and form the assembly $\varphi_{S k}$, according to 2$), 3$ ) search target to sort the priority degree of load bus, search one by one, and then consider the following two situation:

a) If find $N_{i} \in \varphi_{S k}$ make $P_{S k}+P_{N i} \geq 0, N_{i}$ incorporated into $S_{k}$, mark $M k_{i}=0$, and line between $S_{k}$ and $N_{i}$ mark $L_{k i}=1$, the new output power of island source $P_{S k}=P_{S k}+P_{N i}$, find next $S_{k}\left(k=k+1\right.$, if $k=N_{S}$, then $\left.k=1\right)$, continue the step 2).

b) For every situation $\forall N_{i} \in \varphi_{S k}$, if $P_{S k}+P_{N i}<0$ or $\varphi_{S k}=\varnothing$, mark all line which between $S_{k}$ and $N_{i}, L_{k i}=0$, shift out $S_{k}$ from $\Phi_{S}$, if $\Phi_{S} \neq \varnothing$, renumber all island source belong to $\Phi_{S}$, set $k=1$, continue to the step 2), otherwise finish the search of all island source and in step 3).

3)After above 1), 2) steps, disconnect all line which marks $L=0$, every island was single power supply system.

\section{ANALYSIS OF EXAMPLES}

\section{A. Parameter Settings}

In this paper, taking IEEE 33 bus distribution system for example, as shown in Figure 1, and number all nodes and lines, the parameter of branch impedance and power was show in document[9].

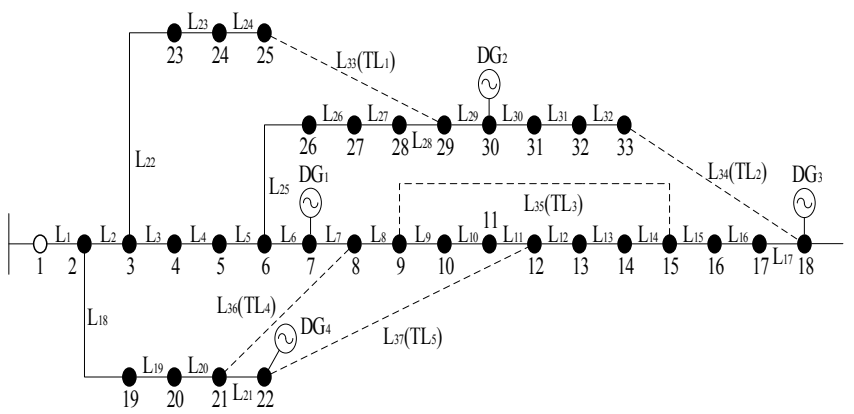

FIGURE I. STRUCTURE OF IEEE-33 DISTRIBUTION SYSTEM

All lines can be divided into primary lines $\left(\mathrm{L}_{1} \sim \mathrm{L}_{5}\right)$, branch lines $\left(\mathrm{L}_{6} \sim \mathrm{L}_{32}\right)$ and tie line $\left(\mathrm{L}_{33} \sim \mathrm{L}_{37}\right) . v_{c i}=3 \mathrm{~m} / \mathrm{s}, v_{r}=14 \mathrm{~m} / \mathrm{s}, v_{c o}=24$ $\mathrm{m} / \mathrm{s}, \mathrm{c}=11.1, \alpha=\beta=0.85, P_{D a y}=54.17 \%[10] . \mathrm{DG}_{1}$ (wind power generation, $P_{\max }=1500 \mathrm{~kW}, \mu=65 \%$ ), $\quad \mathrm{DG}_{2}$ (wind power generation, $P_{\max }=1000 \mathrm{~kW}, \mu=60 \%$ ), $\mathrm{DG}_{3}$ (photovoltaic power generation, $P_{\max }=1200 \mathrm{~kW}, \mu=35 \%$ ) and $\mathrm{DG}_{4}$ (photovoltaic power generation, $P_{\max }=800 \mathrm{~kW}, \mu=30 \%$ ). In this examples, fault recovery time is equal to failure assessment cycle $(t=\mathrm{T})$.

\section{B. The analysis of example's results}

Calculate the risk of situation a(With no TL and DG, and no failure recovery after accident), situation $b$ (With only TL, and limit transfer power $P_{T L}=300 \mathrm{~kW}$ ), situation c(With only DG, and $P_{D G}=\mu \cdot P_{\max }$ ), and situation $\mathrm{d}($ With TL and DG, $\left.P_{T L}=300 \mathrm{~kW}, P_{D G}=\mu \bullet P_{\max }\right)$. Take L3 fault accident for example $\left(\lambda_{E 3}=7.26 \times 10^{-4}, B=0.2621, \gamma_{L}=1.2\right)$. The result is shown in Table 1.Result shows that system does not take any recovery program will lead to larger load bus loss risk; Use TL to transfer power can reduce the loss risk to a greater degree, but it will increase the overload risk value of system. The solution only by DG can restore widespread power outages area. The scheme which use TL and DG to restore power supply can reduce the Load bus risk value to the greatest extent, and improve the probability of the DG power supply,

TABLE I. THE COMPARE OF RECONFIGURATION AND RISK IN DIFFERENT SITUATION AFTER THE BREAKDOWN OF LINE 3

\begin{tabular}{|c|c|c|c|c|c|c|c|c|}
\hline \multirow{2}{*}{$\begin{array}{l}\text { Different } \\
\text { situation }\end{array}$} & \multicolumn{5}{|c|}{ System fault recovery scheme } & \multirow{2}{*}{$\begin{array}{c}\text { load bus loss } \\
\text { risk statistical } \\
\text { value } / 10^{-4}\end{array}$} & \multirow{2}{*}{$\begin{array}{c}\text { Line overload } \\
\text { risk statistical } \\
\text { value } 10^{-4}\end{array}$} & \multirow{2}{*}{$\begin{array}{c}\text { Comprehensive } \\
\text { risk statistical } \\
\text { value } 10^{-4}\end{array}$} \\
\hline & Break line & $T L$ & $D G$ and $_{I}$ & probability & Outage bus & & & \\
\hline $\mathrm{a}$ & - & - & & - & $4 \sim 18,26 \sim 33$ & 5.373 & 0.105 & 4.319 \\
\hline $\mathrm{b}$ & $\begin{array}{c}\text { L7,L9,L10,L14, } \\
\text { L25,L29 }\end{array}$ & $\begin{array}{c}\mathrm{TL}_{1}, \mathrm{TL}_{4}, \\
\mathrm{TL}_{5}\end{array}$ & & - & $\begin{array}{c}4 \sim 7,10,15 \sim 18, \\
30 \sim 33 \\
\end{array}$ & 3.742 & 0.499 & 3.094 \\
\hline $\mathrm{c}$ & $\begin{array}{l}\text { L7,L9,L10,L14, } \\
\text { L25,L29 }\end{array}$ & - & $\begin{array}{l}\mathrm{DG}_{1} \\
\mathrm{DG}_{2} \\
\mathrm{DG}_{3} \\
\end{array}$ & $\begin{array}{l}42.3 \% \\
44.2 \% \\
35.4 \% \\
\end{array}$ & $13,32,33$ & 3.436 & 0.105 & 2.770 \\
\hline d & $\begin{array}{c}\text { L7,L9,L10,L14, } \\
\text { L25,L29,L32 }\end{array}$ & $\begin{array}{l}\mathrm{TL}_{1} \\
\mathrm{TL}_{4} \\
\mathrm{TL}_{5} \\
\end{array}$ & $\begin{array}{l}\mathrm{DG}_{1} \\
\mathrm{DG}_{2} \\
\mathrm{DG}_{3} \\
\end{array}$ & $\begin{array}{l}66.8 \% \\
46.4 \% \\
40.3 \% \\
\end{array}$ & 10,33 & 2.020 & 0.463 & 1.709 \\
\hline $\mathrm{e}$ & - & $\begin{array}{l}\mathrm{TL}_{1} \\
\mathrm{TL}_{4} \\
\mathrm{TL}_{5}\end{array}$ & & - & $\begin{array}{l}- \\
-\end{array}$ & $\begin{array}{c}1.568 \\
2.8787 \\
3.4188\end{array}$ & $\begin{array}{l}25.139 \\
4.6142 \\
12.396\end{array}$ & - \\
\hline
\end{tabular}




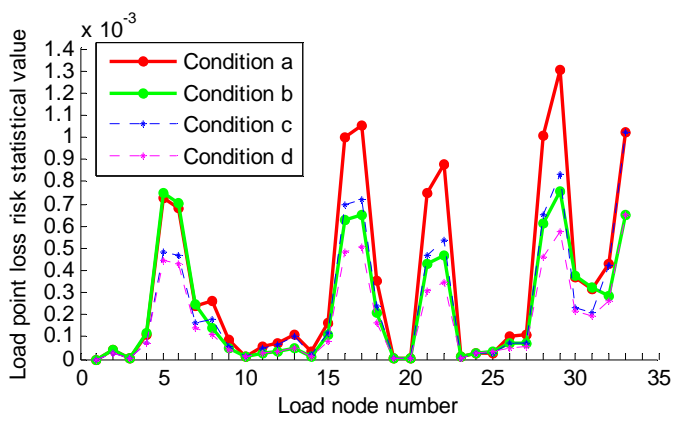

FIGURE II. THE STATISTICS VALUE OF USER LOSS RISK OF NODE IN DIFFERENT SITUATIONS OF SYSTEM

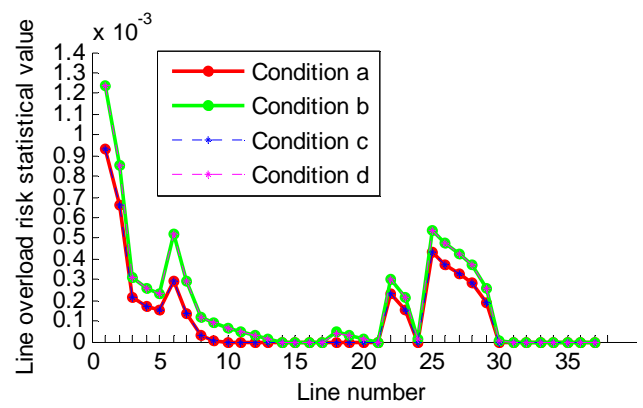

FIGURE III. THE STATISTICS VALUE OF OVERLOAD RISK OF LINE IN DIFFERENT SITUATIONS OF SYSTEM

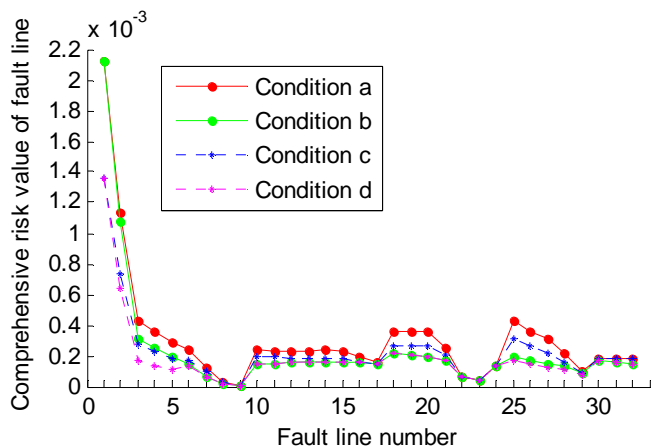

FIGURE IV. THE INTEGRATED VALUE OF RISK OF FAULTY LINE IN DIFFERENT SITUATIONS OF SYSTEM

TABLE II. THE TOTAL VALUE OF RISK AND IT'S IMPROVEMENT DEGREE IN DIFFERENT SITUATIONS

\begin{tabular}{ccccccc}
\hline $\begin{array}{c}\text { Situ- } \\
\text { atio } \\
n\end{array}$ & $\begin{array}{c}\text { Total statistical } \\
\text { value of load bus } \\
\text { loss risk/10 }\end{array}$ & $\begin{array}{c}\text { Total statistical } \\
\text { value of line } \\
\text { overload risk } / \mathbf{1 0}^{-3}\end{array}$ & $\begin{array}{c}\text { Total statistical } \\
\text { value of } \\
\text { comprehensive } \\
\text { risk/10 }\end{array}$ \\
\hline a & 11.3 & - & 4.58 & - & 10.02 & - \\
b & 8.90 & $(-30.6 \%)$ & 6.76 & $(+47.6 \%)$ & 7.68 & $(-23.4 \%)$ \\
c & 8.06 & $(-29.2 \%)$ & 4.58 & $(0)$ & 7.36 & $(-26.6 \%)$ \\
d & 5.83 & $(-48.8 \%)$ & 6.76 & $(+47.6 \%)$ & 6.01 & $(-40.0 \%)$ \\
\hline
\end{tabular}

And the line overload risk value doesn't increase on the basis of scheme, so it is the preferred solution for system failure recovery. But the scheme which only use one TL to restore power supply may make the structure of system instability, and the load bus voltage is too low, there will be much low voltage loss risk, and the line overload risk is more than limit value, so this plan is not desirable.
The statistics value of load bus loss risk and line overload risk was showed respectively in Figure 2 and Figure 3.Result shows that system use TL and DG to recover power supply after failure can effectively reduce the partial load bus loss risk in system. In Figure 4, the total value of risk and it's improvement degree is showed in Table 2.

\section{CONCLUSION}

This paper put forward with risk assessment method of distribution network with DG, evaluation index include load bus loss and line overload and they comprehensive risk index, the method considered the factor of probabilistic power supply of DG. Based on "N-1" safety criteria and find the vulnerable nodes and lines through statistical analysis, it can evaluate risk degree of system. At the same time based on the heuristic algorithm, the fault restoration scheme of power distribution system is proposed, which use the tie line to transfer load at first and then through DG islanding to restore power supply. Finally take IEEE 33 bus distribution system for example, calculation results confirmed the effectiveness and feasibility of this method.

\section{ACKNOWLEDGMENT}

My paper is supported by the Project Supported by National Natural Science Foundation of China (NSFC)(No. 61472128,61173108 ) and the Key project of Natural Science Foundation of Hunan Province (No.14JJ2150).

\section{REFERENCES}

[1] YUAN Xiuguang, HUANG Chun, ZHANG Lei. Reliability Evaluation of Distribution Network Considering Islanded Operation of Microgrid[J] .Power System Technology,2015,39(3):690-697(in Chinese).

[2] LI Chunyan,YANG Qiang,WEI Wei.Distribution network reconfiguration considering correlation between wind-speed and load[J].Electric Power Automation Equipment,2016,36(2):148-160.(In Chinese)

[3] ZHOU Quan,XIE Huili,ZHENG Bolin,et al.Hybrid Algorithm Based Coordination Between Distribution Network Fault Reconfig- uration and Islanding Operation[J].Power System Technology,2015,39(1):136142(in Chinese)

[4] Pang Qingle,Gao Houlei,Li Tianyou.Load balancing based fault service restoration for smart distribution grid[J].Power System Technology,2013,37(2):342-348(in Chinese).

[5] Kumar Y,Das B,Sharma J.Multiobjective,multiconstraint service restoration of electric power distribution system with priority customers[J].IEEE Transactions on Power Delivery,2008,23(1):261-270.

[6] Atwa Y M,EI-Saadany E F.Reliability evaluation for distribution system with renewable distributed generation during islanded mode of operation[J].IEEE Trans. on Power Systems,2009,24(2):572-581.

[7] Xu Yuan,Wang Ke,Chen Bo.Reliability and risk assessment techniques for distribution networks with distributed generations [J].Proceedings of the CSU-EPSA,2013,25(4):117-121.

[8] LIU Ruoxi,ZHANG Jianhua,WU Di.Distribution network theory static security evaluation index research[J].Power System Protection and Control,2011,39(15):89-96.

[9] Baran M,Wu F.Network reconfiguration in distribution systems for loss reduction and load balancing[J].IEEE Trans on Power Delivery, 1989,4(2):1401-1407.

[10] Chen Guang,Dai Pan,Zhou Hao,et al.Distribution system reconfiguration considering distributed generators and plug-in electric vehicles[J] .Power System Technology,2013 , 37(1) : 82-88(in Chinese). 